\title{
RATIONAL DESIGNING OF SUSTAINED RELEASE MATRIX FORMULATION OF ETODOLAC EMPLOYING HYPROMELLOSE, CARBOMER, EUDRAGIT AND POVIDONE
}

\author{
NILESH N. MAHAJAN*, POOJA WADHAVANE, DEBARSHI KAR MAHAPATRA \\ Department of Pharmaceutics, Dadasaheb Balpande College of Pharmacy, Nagpur 440037, Maharashtra, India \\ Email: nmmahajan78@gmail.com
}

Received: 06 May 2017 Revised and Accepted: 02 Nov 2017

\section{ABSTRACT}

Objective: The existing investigation represents a challenge in formulating etodolac oral controlled-release tablets employing five most prominent hydrophilic release rate retardant polymers like hydroxypropyl methylcellulose (HPMC) grades K100M, K4M, carbopol 934P, eudragit RS100, and polyvinylpyrrolidone K90 which are non-toxic substances, cost-effective, and easily available.

Methods: Utilizing the wet granulation method, employing talc, anhydrous lactose, and magnesium stearate, the batches were formulated. The precompression and post-compression characteristics were assessed according to the specified protocols. The formulations were accessed for their ability to release the drug in the simulated gastric media and the obtained results were fitted into various kinetic models to determine the probable drug release mechanism(s). A short-term stability study (for $90 \mathrm{~d}$ duration) was also performed.

Results: The densities (bulk and tapped) lie in the range of $0.74-0.75 \mathrm{~g} / \mathrm{cm}^{3}$ and $0.84-0.87 \mathrm{~g} / \mathrm{cm}^{3}$, respectively, representing an excellent precompression characteristic. The drug content was found in the range 97.61-99.04\%. The most proper in vitro drug release was observed for the formulation F6 (101.84\%) due to the optimum concentration of carbomer, hypromellose, and povidone combination which retarded the drug release; following the diffusion cum erosion mechanism(s) (called anomalous diffusion) and also illustrated comparable drug release with marketed formulation (Etogesic ${ }^{\circledR}$-ER $600 \mathrm{mg}$ ). The batches did not show any significant changes under accelerated conditions.

Conclusion: The judiciously planned fabrication of the matrix formulations possess the ability to decrease the frequency of drug administration to twice-daily along with minimizing the blood level fluctuations, which ultimately leads to enhanced patient compliance and better therapeutic regimens.

Keywords: Etodolac, Matrix, Release Mechanism, Sustained, Stability, Tablet

(C) 2017 The Authors. Published by Innovare Academic Sciences Pvt Ltd. This is an open-access article under the CC BY license (http://creativecommons.org/licenses/by/4.0/] DOI: http://dx.doi.org/10.22159/ijpps.2017v9i12.19702

\section{INTRODUCTION}

Etodolac (ETO) is a biopharmaceutics classification system (BCS) Class-II drug used primarily as non-steroidal anti-inflammatory (NSAID) drugs for treating pain related to arthritis. ETO decreases the synthesis of peripheral prostaglandins which are involved in mediating inflammation. It binds to the upper portion of the cyclooxygenase (COX) enzyme active site and prevents its substrate, arachidonic acid, from entering the active site. It is 5-50 times more selective for COX-2 than COX-1, which makes it therapeutically more efficient in managing arthritis-related pain [1-2]. The drug is having a half-life of $6.4 \mathrm{~h}$ and exhibit $>99 \%$ protein binding, primarily to albumin. The mean apparent volume of distribution of the drug is $390 \mathrm{ml} / \mathrm{kg}$, which represents ETO is extensively metabolized in the liver. Renal elimination remained the chief excretion route for both etodolac and its metabolites (72\%). Metabolites found in urine (with percents of the administered dose) includes; unchanged ETO (1\%), ETO glucuronide (13\%), hydroxylated metabolites (6-, 7-, and 8-OH; $5 \%)$, hydroxylated metabolite glucuronides $(20 \%)$, and unidentified metabolites (33\%). Fecal excretion accounts for $16 \%$ of its elimination. It is not known whether ETO is excreted in human milk; however, based on its physical-chemical properties, excretion into breast milk is expected [3-4].

At present, several anti-inflammatory drugs for arthritis are currently employed in the management. Yet, it is essential to achieve the therapeutic regimen by maintaining the constant desired systemic concentration of the drug during the treatment period to meet required patient fulfilment. On the other hand, the cost remained a critical factor among the patient population to sustain a long duration of therapy. Probably, the treatment or rather the management involved the entire tenure of patient's life, ultimately causing a financial burden. Therefore, this might be a maiden attempt to design a Generic based development of ETO formulation which may meet the patient demand by fulfilling the key features of delivering identical bioequivalency, holding high similarity index, and demonstrate quite comparable in vitro drug release profiles.

The objectives of the present study includes (1) formulating ETO sustained release matrix tablets using five hydrophilic release rate retardant polymers such as HPMC K100M, HPMC K4M, carbopol 934P, eudragit RS100, and polyvinylpyrrolidone K90; (2) determining the role of rate controlling agents in the formulation by in vitro dissolution studies and determining the pattern of drug release from the matrix formulations using diverse release models; and (3) studying the stability of the fabricated batch under shortterm accelerated conditions. This research was done with an intention to fabricate sustained release tablet formulations which will have perspectives of generic medicine.

\section{MATERIALS AND METHODS}

\section{Materials}

ETO was obtained as a generous gift from Emcure Pharmaceuticals Ltd., Mumbai, India. HPMC K4M and HPMC K100M were obtained from Virgo Pharmaceutical Ltd., Goa, India. Eudragit RS100 was procured from Glenmark Pharmaceutical, Ltd. Nasik, India. Polyvinylpyrrolidone K90, carbopol 934P, lactose, talc, magnesium stearate, potassium dihydrogen phosphate, and isopropyl alcohol were purchased from Molychem Ltd., Mumbai, India. All other procured chemicals were of analytical grade. Etogesic $₫$ ER $600 \mathrm{mg}$ (Cadila Pharmaceuticals Ltd.) was purchased from the local pharmacy store located in Nagpur, Maharashtra, India.

\section{Instruments}

Double-beam Shimadzu ${ }^{\circledR}$ ultraviolet-visible spectrophotometer (Model UV-1800, Kyoto, Japan) was used for the spectroscopic 
analysis. The system comprised of a pair of $10 \mathrm{~mm}$ path length matched quartz cells and a beam delivering unit of the spectral bandwidth of $1 \mathrm{~nm}$ with a wavelength accuracy of $\pm 0.3 \mathrm{~nm}$, connected with a computer. Shimadzu® electronic balance (Model AUW220D, Kyoto, Japan) was employed for the weighing of chemicals. Shimadzu ${ }^{\circledR}$ IRAffinity-1S instrument was employed for carrying out the FT-IR analysis. Vernier caliper (Indian caliper, Ambala, India), Pfizer hardness tester (Pfizer, Spacelabs, India), Dissolution test apparatus (Electrolab, India), and Roche friabilator (Electrolab, India) were employed for the evaluation of prepared tablets. Stability chamber (Bio-Technics, India) was used for conducting the accelerated stability studies.

\section{Preparation of ETO matrix tablet}

For the preparation of formulations, the active ingredient ETO, polymers and diluents were sifted through sieve \#44. Using the wet granulation method, the matrix tablets containing $600 \mathrm{mg}$ of ETO were prepared by mixing all the above ingredients (except lubricants) in a mortar, then add granulating fluid, i.e. isopropyl alcohol and the dry mixture were granulated and uniform was done till it forms uniform granules.

The dried granules were sifted through sieve \#22. The wet granules of above step were taken into a rapid air-dryer. Then the wet mass was dried at an inlet temperature of $50{ }^{\circ} \mathrm{C}$ and loss on drying (LOD) of the dried granules should not more than 3\%. After drying, magnesium stearate was added to dried granules to improve its flow property. The prepared blend was compressed into tablets by using $17 \mathrm{~mm}$ punch using 10-station tablet punching machine. Table 1 portrays the complete formulation chart.

Table 1: Formulation of etodolac matrix tablet

\begin{tabular}{|c|c|c|c|c|c|c|c|c|c|}
\hline Ingredients & F1 & F2 & F3 & F4 & F5 & F6 & F7 & F8 & F9 \\
\hline Etodolac & 600 & 600 & 600 & 600 & 600 & 600 & 600 & 600 & 600 \\
\hline HРMC K100M & 15 & 22.5 & 37.5 & 15 & 30 & 22.5 & - & - & - \\
\hline HPMC K4M & 30 & 45 & 18.75 & - & - & - & - & - & - \\
\hline Carbopol 974 & - & - & - & 7.5 & 10 & 8.75 & - & - & - \\
\hline Eudragit RS 100 & - & - & - & - & - & - & 7.5 & 15 & 11.25 \\
\hline Polyvinyl pyrroliodone K 90 & 1.5 & 7.5 & 7.5 & 1.5 & 3.75 & 3.75 & - & - & - \\
\hline Anhydrous lactose & 53.5 & 27 & 38.25 & 76 & 58.25 & 67 & 92.5 & 87 & 90.25 \\
\hline Talc & 45 & 45 & 45 & 45 & 45 & 45 & 45 & 45 & 45 \\
\hline Magnesium stearate & 5 & 3 & 3 & 5 & 3 & 5 & 5 & 3 & 3 \\
\hline Isopropyl alcohol & q. s. & q. s. & q. s. & q. s. & q. $s$. & q. s. & q. s. & q. s. & q. s. \\
\hline
\end{tabular}

The ingredients are expressed in $\mathrm{mg}$. The average weight of tablet is $750 \mathrm{mg}$.

\section{Drug-interaction studies}

The possibility of any such interaction between the drug (ETO) and the five utilized polymers; HPMC K100M, HPMC K4M, carbopol 934P, eudragit RS100, and polyvinylpyrrolidone K90 was monitored by Fourier transformed infrared (FT-IR) spectroscopy to observe the compatibility and inherent stability of the formulation. Any change in the physical mixture of drug and polymer was reported, which may be interpreted as an interaction [5].

\section{Evaluation of granule properties}

The final granule blend was characterized by the physical parameters such as bulk density, tapped density, angle of repose, Hausner's ratio and Carr's index. The prepared granules were initially evaluated suitably for their characteristic parameters such as angle of repose (by funnel method), bulk density and tapped density (by cylinder method). The Hausner's ratio was determined by the pharmacopoeia formula [6].

\section{Evaluation of tablet characteristics}

The fabricated ETO tablets were properly evaluated in terms of their desired attributes of thickness (using Vernier Calipers), weight variation (according to the IP guidelines), hardness (employing Pfizer hardness tester), friability (Roche friability testing apparatus), and content uniformity (by crushing 20 tablets and weighed powder equivalent to $100 \mathrm{mg}$ of ETO and dissolving in $100 \mathrm{ml}$ of alcohol, stirred and filtered; termed as 'Solution A'. $5 \mathrm{ml}$ of the Solution A was further diluted with $10 \mathrm{ml}$ alcohol; termed as 'Solution B'. $1 \mathrm{ml}$ of the Solution B was again diluted with $10 \mathrm{ml}$ alcohol and the absorbance was recorded at $273 \mathrm{~nm}$ with the help of UV spectrophotometer) [7].

\section{In vitro dissolution studies}

The in vitro drug release studies for the prepared batches were performed in $900 \mathrm{ml}$ of simulated gastric fluid (dissolution medium having $\mathrm{pH} 1.2$ ) for $2 \mathrm{~h}$ initially using USP 33 (Type II) apparatus, maintained at $37 \pm 0.5{ }^{\circ} \mathrm{C}$ temperature at a speed of $100 \mathrm{rpm}$. After 3 $\mathrm{h}$, the dissolution was replaced by phosphate buffer saline media (pH 7.4) and continued for additional $10 \mathrm{~h}$. After every $1 \mathrm{hr}, 5 \mathrm{ml}$ of the sample was withdrawn using a calibrated pipette for the $12 \mathrm{~h}$ duration. Consistently, an equivalent amount of fresh dissolution medium was added to maintain the sink conditions. The drug content was determined using UV-visible spectrophotometer at 273 $\mathrm{nm}$ [8]. The release studies were executed in triplicate manner. The obtained results were compared with the marketed formulation Etogesic ${ }^{\circledR}$-ER $600 \mathrm{mg}$ (Cadila Pharmaceuticals Ltd.).

\section{Kinetic modelling of drug release}

The dissolution profiles of all the batches were fitted to various models such as zero-order (drug release rate is independent of its concentration), first-order (drug release rate is concentration dependent), Higuchi (release of drug from an insoluble matrix as square root of time dependent process), Hixon-Crowell (drug release from systems due to change in the surface area and the diameter of particle), and Korsmeyer and Peppas (drug release till the polymer chains rearrange to equilibrium state) in order to determine the mechanism of drug release from the formulation [9]. Based on the goodness-or fittest, the most appropriate model was selected.

\section{Short-term stability study}

The optimized batch (F6) was subjected to accelerated stability conditions $\left(40{ }^{\circ} \mathrm{C} \pm 2{ }^{\circ} \mathrm{C}\right.$ and $\left.75 \% \pm 5 \% \mathrm{RH}\right)$ for the duration of $90 \mathrm{~d}$. The tablet was packed in an aluminium foil and kept inside a PVC bottle. After the completion of the study, the parameters such as hardness, friability, weight variation, content uniformity, and thickness were determined using pharmacopoeia guidelines [10].

\section{Statistical analysis}

The statistical analysis applied was a one-way analysis of variance (ANOVA) with least significant difference (LSD) multiple comparison procedures, keeping the statistical probability (P) value of $<0.05$ as a significant difference.

\section{RESULTS AND DISCUSSION}

The tablet fabrication was done employing the biconcave flat punch having a dimension of $17 \mathrm{~mm}$. The produced tablets were detected to be free from any problems like capping, picking, and chipping. 
The FTIR spectra for the drug (ETO), polymers (HPMC K100M, HPMC K4M, carbopol 934P, eudragit RS100, and polyvinylpyrrolidone K90), and drug-polymer blends (ETO-HPMC K100M, ETO-HPMC K4M, ETO-carbopol 934P, ETO-eudragit RS100, and ETO-polyvinyl pyrrolidone K90) were recorded to determine the possible interactions. Predominantly, the drug displayed characteristic peaks at $3583,3022,2966,1740,1260,1141 \mathrm{~cm}^{-1}$, respectively. In the physical mixture with the polymer, no such overlapping peaks were noticed, which confirmed no such drugpolymer interactions. The evaluated granules were observed to be acceptable as per the limits. The densities (both bulk and tapped) lie in the range of $0.74-0.75 \mathrm{~g} / \mathrm{cm}^{3}$ and $0.84-0.87 \mathrm{~g} / \mathrm{cm}^{3}$, respectively, which represented an excellent packing of the granules. The angle of repose was observed to be $26^{\circ}-30^{\circ}$ for the batches which indicated reasonably satisfactory flow property. The calculated Hausner's ratio and Carr's index were in the order of 1.08-1.14, which may be interpreted as relatively good packing ability. In short, the tablet blend demonstrated fairly good micromeritic attributes essential for exhibiting sustained release characteristics. The pre-compression parameters are shown in table 2.

Table 2: Evaluation of pre-compression parameters for extended release etodolac matrix tablets

\begin{tabular}{lllll}
\hline Formulation & Angle of repose ${ }^{\#}\left({ }^{\circ}\right)$ & $\begin{array}{l}\text { Bulk density } \\
\text { (in g/ml) }\end{array}$ & $\begin{array}{l}\text { Tapped density } \\
\text { (in g/ml) }\end{array}$ & $\begin{array}{l}\text { Compressibility }^{\#} \\
\text { Index (in \%) }\end{array}$ \\
\hline F1 & $29.17 \pm 0.52$ & $0.742 \pm 0.013$ & $0.848 \pm 0.00745$ & $12.42 \pm 1.94$ \\
F2 & $30.08 \pm 0.53$ & $0.76 \pm 0.0098$ & $0.862 \pm 0.0022$ & $11.7 \pm 1.24$ \\
F3 & $28.02 \pm 0.48$ & $0.763 \pm 0.013$ & $0.838 \pm 0.0065$ & $8.87 \pm 1.75$ \\
F4 & $29.15 \pm 0.15$ & $0.756 \pm 0.014$ & $0.856 \pm 0.0051$ & $11.97 \pm 0.99$ \\
F5 & $26.66 \pm 0.53$ & $0.772 \pm 0.0074$ & $0.858 \pm 0.0056$ & $11.06 \pm 1.13$ \\
F6 & $27.39 \pm 0.34$ & $0.77 \pm 0.0062$ & $0.862 \pm 0.0058$ & $1.67 \pm 0.025$ \\
F7 & $30.74 \pm 0.47$ & $0.784 \pm 0.0037$ & $0.878 \pm 0.0036$ & $10.77 \pm 0.73$ \\
F8 & $28.19 \pm 0.30$ & $0.784 \pm 0.0031$ & $0.849 \pm 0.0045$ & $7.77 \pm 0.61$ \\
F9 & $29.14 \pm 0.65$ & $0.781 \pm 0.0055$ & $0.877 \pm 0.0065$ & $1.13 \pm 0.022$ \\
\hline
\end{tabular}

$\# \mathrm{n}=6$ (The number of samples are 6)

The evaluation parameters revealed that the prepared matrix tablet batches presented the essential attributes. All the fabricated batches displayed the necessary hardness of more than $5 \mathrm{~kg} / \mathrm{cm}^{2}$ along with friability value of less than $1 \%$, ultimately representing the required strength and resistibility of the matrix formulations. The Eudragit RS100 and anhydrous lactose combination were found to exhibit a profound role in imparting hardness to the formulation as compared to HPMC. Similar characteristics were imparted with carbopol 974 and anhydrous lactose combination to the formulations. The drug content was identified to be in the range of $97.61-99.04 \%$.

A weight variation of $<1 \%$ was observed for the prepared batches, indicating almost uniform drug content in all the ETO formulations. The post-compression parameters are described in table 3 .

Table 3: Evaluation of post-compression parameters for extended release etodolac matrix tablets

\begin{tabular}{|c|c|c|c|c|}
\hline Formulation & Thickness" (in mm) & Friability" (\%) & Hardness ${ }^{\#}\left(\mathrm{~kg} / \mathrm{cm}^{2}\right)$ & Drug content $^{\#}(\%)$ \\
\hline F1 & $5.04 \pm 0.11$ & $0.59 \pm 0.03$ & $5.2 \pm 0.19$ & $98.09 \pm 0.51$ \\
\hline $\mathrm{F} 2$ & $5.1 \pm 0.10$ & $0.64 \pm 0.07$ & $5.3 \pm 0.08$ & $97.14 \pm 0.87$ \\
\hline F3 & $5.06 \pm 0.18$ & $0.62 \pm 0.06$ & $5.4 \pm 0.12$ & $99.04 \pm 0.66$ \\
\hline F4 & $5.06 \pm 0.11$ & $0.67 \pm 0.03$ & $5.7 \pm 0.17$ & $96.19 \pm 0.92$ \\
\hline F5 & $5.1 \pm 0.16$ & $0.54 \pm 0.04$ & $5.6 \pm 0.11$ & $99.52 \pm 0.49$ \\
\hline F6 & $5.02 \pm 0.13$ & $0.68 \pm 0.08$ & $5.4 \pm 0.09$ & $99.04 \pm 0.83$ \\
\hline F7 & $5.02 \pm 0.18$ & $0.52 \pm 0.06$ & $5.3 \pm 0.10$ & $96.66 \pm 0.76$ \\
\hline F8 & $5.14 \pm 0.15$ & $0.63 \pm 0.09$ & $5.7 \pm 0.07$ & $98.57 \pm 0.58$ \\
\hline F9 & $5.12 \pm 0.16$ & $0.69 \pm 0.06$ & $5.9 \pm 0.13$ & $97.61 \pm 0.94$ \\
\hline
\end{tabular}

\# $\mathrm{n}=6$ (The number of samples are 6)

The majority of the release controlling agent containing formulations displayed a steadily sustained release attribute as compared to conventional dosage forms. The release of drug from the hydrophilic matrix involves a complex interaction between drug dissolution, solubilization, diffusion, and erosion mechanism(s). Formulation F1 showed the maximum drug release within $4 \mathrm{~h}$ due to lowest polymer concentration. Formulation F2 demonstrated a low drug release up to $12 \mathrm{~h}$ due to the high polymer concentration of HPMC K4M. Formulation F3 consists of a proper ratio of polymers such as HPMC K4M and HPMC K100M which retard the drug release of $90.22 \%$ in the duration of $12 \mathrm{~h}$.

Formulation $\mathrm{F} 4$ exhibited the cumulative drug release of $102.45 \%$ within $5 \mathrm{~h}$. The reason may be the absence of HPMC K4M and low polymeric concentration of povidone $(1.5 \mathrm{~g})$. It may be believed that the drug diffuses out of the matrix forming pores from which the solvent molecules entered that leads to a fast dissolution of the drug. From the hypothetical pre-formulation assumption of formulation development based on in vitro dissolution and in vivo data of innovator drug, the batch does not hold good in maintaining a sustained release attribute and was discarded for further studies.
Formulation F5 presented a similar drug release profile with that of formulation F3, where a low drug release was exhibited up to $12 \mathrm{~h}$ due to high polymer concentration (HPMC K100M). The polymer HPMC K100M on contact with aqueous media forms an intense and viscous gel which results in controlled delivery of the drug. The most proper in vitro drug release was observed in the formulation F6 (101.84\%) due to the optimum concentration of carbomer, hypromellose, and povidone combination which retarded the drug release (fig. 1). The phenomenon of aqueous penetration, swelling of polymer and gel formation, and concurrent actions of drug diffusion and matrix erosion from the formulation were governed by the level of HPMC hydration in the matrix that eventually promotes drug diffusion. On viewing the dissolution chart, it was observed that a burst phenomenon was prevailed in case of formulation F6, in the duration of $3^{\text {rd }}$ to $4^{\text {th }} \mathrm{hr}$ where more than twice the drug was released from the fabricated product. Based on the theoretical release profile of $\mathrm{F} 6$, it may be ascertained that the drug release gets released till the polymer chains rearrange to the equilibrium state.

Formulation F7, having the lowest polymer concentration, represented a fast drug release within $5 \mathrm{~h}$, quite similar to that of 
formulations F1 and F4. The formulation contained only $7.5 \mathrm{~g}$ of eudragit RS100. Formulation F8 offered one of the lowest drug releases up to $12 \mathrm{~h}$. Due to the twice the concentration of polymer eudragit RS100, the drug release was hindered in the intended $12 \mathrm{~h}$ duration. The formulation F9 signified analogous release profile with that of formulation F6. The optimized concentration of polymer eudragit RS100 leads to maximum drug release observed by $100.97 \%$ within $12 \mathrm{~h}$, owing to rate retardant attributes. Although, it is well known that in any anomalous overlapping phenomenon of diffusion, erosion, and solubilization, all three components are closely associated. It may be an insight that the diffusion and erosion mechanism(s) were dominant in case of formulation F3, F6, and F9 as compared to solubilization.

The marketed formulation Etogesic ${ }^{\circledR}$ ER $600 \mathrm{mg}$ (Cadila Pharmaceuticals Ltd.) demonstrated excellent cumulative drug release profile of $108.44 \%$ within $12 \mathrm{~h}$ period. The formulations F3, F6, and F9 showed a comparable drug release profile with that of the marketed preparation. The formulation F6 displayed analogous release with that of the marketed product. On the basis of in vitro drug release data and also from the similarity factor by considering the bio-waiver conditions, it might be predicted that the batch may exhibit bioequivalent result and may hold the perspective of utility as a Generic product in future. However, based on the available data of in vitro dissolution testing, in relation to the innovator drug, an IVIVC might be predicted for the optimized formulation F6 which may be used as a bio-equivalent product. Although, the human volunteer-based study is foremost essential and necessary to establish such profiles in reality. Table 4 highlights the in vitro drug release profile of the fabricated matrix tablet batches and marketed formulation.

The combination of hydroxypropyl methylcellulose (HPMC) grades $\mathrm{K} 100 \mathrm{M}, \mathrm{K} 4 \mathrm{M}$, carbopol 934P, eudragit RS100, and polyvinylpyrrolidone K90 demonstrated that the release is dependent exclusively on the type and amount. In some formulations, F1, F3, and F7 where at $5 \mathrm{~h}$ complete drug release is observed. The optimized formulation F6 comprising of HPMC K100M (22.5 mg), carbopol 974 (8.75 mg), and polyvinylpyrrolidone K 90 (3.75 mg) displayed the highest release of $101.84 \%$. In comparison with the previously reported literature a remarkable difference in the drug release and the pattern was noticed. The ETO tablets fabricated by drug release retardant polymer Kollidon ${ }^{\circledR S R}$ showed $71.67 \%$ after $12 \mathrm{~h} \mathrm{[11].} \mathrm{ETO} \mathrm{tablet} \mathrm{fabricated} \mathrm{with} \mathrm{hydroxyl}$ propyl methyl cellulose E-15, E-50, xanthan gum, and guargum presented $70.81 \%$ drug release after $12 \mathrm{~h} \mathrm{[12].} \mathrm{The} \mathrm{ETO} \mathrm{matrix}$ tablet containing HPMC K100 LVCR and polyox WSR 303 expressed $81.57 \%$ release after $12 \mathrm{~h}$ in basic media [13]

Similarly, the formulation prepared by the combination of tamarind xyloglucan, gellan gum, sodium CMC, and xanthan gum exhibited drug release of $84.51 \%$ for $12 \mathrm{~h}$ [14]. Therefore, while designing twice daily formulation, the fabricated formulation from hydroxypropyl methylcellulose (HPMC) grades K100M, K4M, carbopol 934P, eudragit RS100, and polyvinylpyrrolidone K90 revealed the best results which is quite comparable with the innovator product brand (108.44\%).

Table 4: In vitro drug release profiles of the fabricated batches and comparison with marketed formulation

\begin{tabular}{|c|c|c|c|c|c|c|c|c|c|c|c|}
\hline \multirow{2}{*}{$\begin{array}{l}\text { Time } \\
\text { (h) }\end{array}$} & \multicolumn{11}{|c|}{ Cumulative drug release (\%) \# } \\
\hline & Medium & F1 & F2 & F3 & F4 & F5 & F6 & F7 & F8 & F9 & MP \\
\hline 1 & $\mathrm{pH} 1.2$ & $31.99 \pm 0.12$ & $14.15 \pm 0.51$ & $32.23 \pm 0.24$ & $11.43 \pm 0.27$ & $7.25 \pm 0.18$ & $11.51 \pm 0.42$ & $5.94 \pm 0.28$ & $6.68 \pm 0.09$ & $11.02 \pm 0.71$ & $\begin{array}{l}7.35 \pm \\
0.48\end{array}$ \\
\hline 2 & pH 1.2 & $45.43 \pm 0.33$ & $16.82 \pm 0.69$ & $37.33 \pm 0.98$ & $19.10 \pm 0.40$ & $7.68 \pm 0.62$ & $12.75 \pm 0.91$ & $11.33 \pm 0.70$ & $10.57 \pm 0.37$ & $11.27 \pm 0.16$ & $\begin{array}{l}8.15 \pm \\
0.88\end{array}$ \\
\hline 3 & pH 7.4 & $97.29 \pm 0.47$ & $39.22 \pm 0.76$ & $64.8 \pm 0.56$ & $47.97 \pm 0.81$ & $37.68 \pm 0.92$ & $24.31 \pm 0.68$ & $45.23 \pm 0.20$ & $20.21 \pm 0.89$ & $36.54 \pm 0.86$ & $14.15 \pm 0.39$ \\
\hline 4 & pH 7.4 & $102.98 \pm 0.21$ & $41.43 \pm 0.60$ & $65.84 \pm 0.79$ & $98.30 \pm 0.08$ & $44.76 \pm 0.26$ & $64.33 \pm 0.75$ & $79.83 \pm 0.66$ & $40.3 \pm 0.26$ & $45.23 \pm 0.07$ & $33.86 \pm 0.64$ \\
\hline 5 & pH 7.4 & - & $41.94 \pm 0.74$ & $70.98 \pm 0.24$ & $102.45 \pm 0.23$ & $47.25 \pm 0.42$ & $90.64 \pm 0.37$ & $98.35 \pm 0.50$ & $49.3 \pm 0.62$ & $\begin{array}{l}62.3 \pm \\
0.46\end{array}$ & $40.26 \pm 0.57$ \\
\hline 6 & pH 7.4 & - & $44.89 \pm 0.63$ & $75.94 \pm 0.34$ & - & $47.99 \pm 0.58$ & $95.23 \pm 0.06$ & - & $49.98 \pm 0.46$ & $74.97 \pm 0.14$ & $55.32 \pm 0.80$ \\
\hline 7 & pH 7.4 & - & $48.40 \pm 0.15$ & $77.9 \pm 0.53$ & - & $53.58 \pm 0.49$ & $95.97 \pm 0.31$ & - & $52.02 \pm 0.82$ & $88.55 \pm 0.77$ & $81.59 \pm 0.22$ \\
\hline 8 & pH 7.4 & - & $49.88 \pm 0.44$ & $82.67 \pm 0.71$ & - & $57.86 \pm 0.95$ & $96.95 \pm 0.41$ & - & $53.44 \pm 0.72$ & $90.82 \pm 0.59$ & $83.34 \pm 0.25$ \\
\hline 9 & pH 7.4 & - & $51.92 \pm 0.38$ & $82.73 \pm 0.87$ & - & $58.54 \pm 0.23$ & $97.87 \pm 0.45$ & - & $55.82 \pm 0.38$ & $93.88 \pm 0.67$ & $92.24 \pm 0.54$ \\
\hline 10 & pH 7.4 & - & $52.88 \pm 0.17$ & $84.51 \pm 0.36$ & - & $59.27 \pm 0.88$ & $99.87 \pm 0.73$ & - & $56.95 \pm 0.22$ & $96.26 \pm 0.52$ & $104.65 \pm 0.35$ \\
\hline 11 & pH 7.4 & - & $54.64 \pm 0.30$ & $87.14 \pm 0.65$ & - & $60.05 \pm 0.78$ & $101.66 \pm 0.10$ & - & $59.9 \pm 0.43$ & $98.22 \pm 0.29$ & $105.08 \pm 0.32$ \\
\hline 12 & pH 7.4 & - & $61.61 \pm 0.27$ & $90.22 \pm 0.72$ & - & $67.38 \pm 0.83$ & $101.84 \pm 0.19$ & - & $62.45 \pm 0.55$ & $100.97 \pm 0.61$ & $108.44 \pm 0.49$ \\
\hline
\end{tabular}

\# n = 6 (The number of samples are 6); MP = Marketed Product, Etogesic ${ }^{\circledR}$ ER 600 mg (Cadila Pharmaceuticals Ltd.)

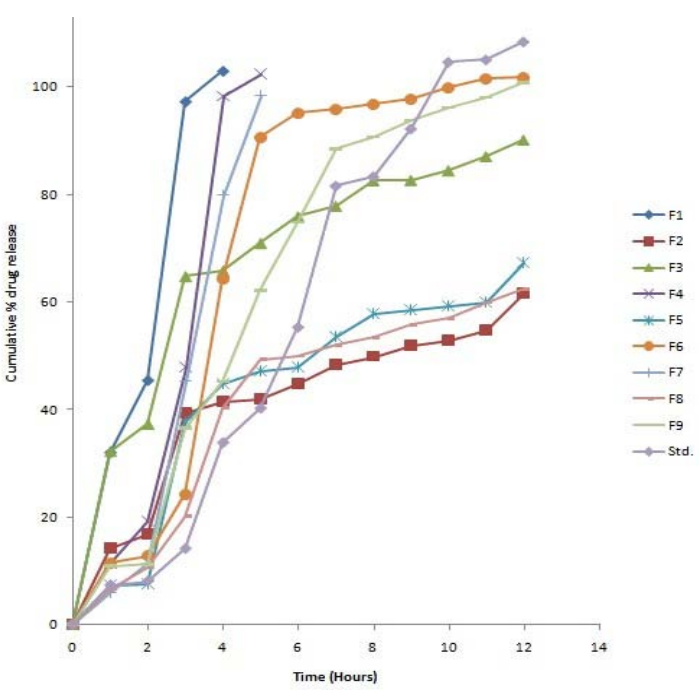

Fig. 1: Dissolution profile of prepared matrix formulations 
$\# \mathrm{n}=6$ (The number of samples are 6); Std. = Standard Drug Etogesic $^{\circledR}$ ER 600 mg (Cadila Pharmaceuticals Ltd.); Formulation F9 described the highest and comparable drug release as compared to the marketed formulation.

Fitting the in vitro drug release data into zero-order, first-order, Higuchi, Korsmeyer-Peppas, and Hixson-Crowell models helped in determining the probable drug release mechanism from the matrix formulations.

Table 5 explains the values of release exponent (n) of the formulations with the probable release mechanism(s). By applying the release models for the formulations F3, F6, and F9, it was found that all the formulations followed the Korsmeyer-Peppas model.

The release exponent (n) was found to be more than 0.5 with good linearity which indicated that drug release involved non-Fickian diffusion which closely overlaps with the swelling erosion study.

It was also observed from the release exponent (n) that drug release was governed by multiple processes and can be defined as an anomalous diffusion, where both diffusion and erosion mechanism works.

Table 5: Kinetic profile of drug release (release exponent, $n$ ) for selected formulations

\begin{tabular}{llll}
\hline Batch & Zero-order & Hixon-Crowell & Higuchi plot \\
\hline F3 & 0.8827 & 0.7666 & 0.9731 \\
F6 & 0.8953 & 0.8659 & 0.9245 \\
F9 & 0.9595 & 0.9107 & 0.9624 \\
\hline
\end{tabular}

The stability study under accelerated conditions of temperature and humidity expressed no as such noticeable alteration in terms of physical appearance, hardness, thickness, drug content, and in vitro drug release profile of the optimized formulation. Although change in drug content $(0.28 \%)$ was detected after the duration of $90 \mathrm{~d}$, that can be considered within the prescribed limits. It may be concluded that the prepared tablet was stable under accelerated conditions. Table 6 depicts the changes before and after the stability study.

Table 6: Short-term stability study of optimized formulation (F6)

\begin{tabular}{lll}
\hline Parameter & Controlled sample $^{\#}$ & Stability sample $^{\#}$ \\
\hline Appearance & White, circular, uncoated tablet & No change observed \\
Thickness $(\mathrm{mm})$ & $5.02 \pm 0.01$ & $5.02 \pm 0.02$ \\
Hardness $\left(\mathrm{kg} / \mathrm{cm}^{2}\right)$ & $5.4 \pm 0.04$ & $5.3 \pm 0.08$ \\
Friability $(\%)$ & $0.68 \pm 0.07$ & $0.66 \pm 0.03$ \\
Drug content $(\%)$ & $99.04 \pm 0.12$ & $98.76 \pm 0.18$ \\
In vitro drug release $\%$ (at $12 \mathrm{~h})$ & $101.84 \pm 0.43$ & $100.29 \pm 0.27$ \\
\hline
\end{tabular}

$\# n=6$ (The number of samples are 6)

\section{CONCLUSION}

The existing investigation represents a challenge in formulating etodolac oral controlled-release tablets employing five most prominent hydrophilic release rate retardant polymers like HPMC K100M, HPMC K4M, carbopol 934P, eudragit RS100, and polyvinylpyrrolidone K90 which are non-toxic substances, costeffective, and easily available. The judiciously planned fabrication of the matrix formulations possesses the ability to decrease the frequency of drug administration to twice-daily along with minimizing the blood level fluctuations, which ultimately leads to enhanced patient compliance and better therapeutic regimens. From the study, it was perceived that the drug release pattern, the attainment of steady state, and the bio pharmacokinetic profile of the formulation to exhibit sustained release is a function of the type(s) and the content of the polymer(s). The formulation F9 displayed the highest drug release of $100.97 \%$, which is quite comparable with that of marketed formulation. The research outcomes encouraged and opened new avenues for developing sustained release formulations capable of providing twice-daily attribute as "generic medicine". The work additionally bears the perspective in translating the fabricated formulation from lab to commercial level after some regulatory checks.

\section{AUTHORS CONTRIBUTION}

Nilesh N. Mahajan, has provided the design, intellectual content, innovations, and protocol for conducting the experiment along with mentorship.

Pooja Wadhavane, has majorly performed the experiment in the laboratory.

Debarshi Kar Mahapatra, has a minor role in the conducting the experiment in the laboratory, analysis of obtained data, and sincerely authored the article.

\section{CONFLICT OF INTERESTS}

The authors declare that there is no conflict of interest regarding the publication of this article.

\section{REFERENCES}

1. Mahapatra DK, Bharti SK. editors. Handbook of Research in Medicinal Chemistry. Ontario: Apple Academic Press; 2017.

2. Pilli R, Nagabhushanam MV, Kadali SK. Etodolac dissolution improvement by preparation of solid dispersions with cyclodextrin complexes. Int J Pharm Sci Res 2014;5:4774-91.

3. Kumar BP, Sumalatha YS. Formulation development and evaluation of floating tablets of etodolac. World J Pharm Pharm Sci 2015;4:1516-32.

4. Ibrahim MM, Mohamed EN, El-Setouhy DA, Fadlalla MA. Polymeric surfactant based etodolac chewable tablets: formulation and in vivo evaluation. AAPS PharmSciTech 2010;11:1730-7.

5. Dangre PV, Godbole MD, Ingale PV, Mahapatra DK. Improved dissolution and bioavailability of eprosartan mesylate formulated as solid dispersions using conventional methods. Indian J Pharm Edu Res 2016;50:S209-S217.

6. Panchal KK, Chotai NP. Formulation development and in vitro evaluation of controlled release matrix tablet of etodolac. Indian J Pharm Edu Res 2013;47:39-48.

7. Shetty P, Kumar R, Suvarna P, Swamy VB. Design and evaluation of sustained release matrix tablets of etodolac. Asian J Pharm Tech 2016;6:1-4.

8. Patil MD, Mahapatra DK, Dangre PV. Formulation and in vitro evaluation of once-daily sustained release matrix tablet of nifedipine using rate retardant polymers. Inventi PharmTech 2016;4:1-7.

9. Godbole MD, Mahapatra DK, Khode PD. Fabrication and characterization of the edible jelly formulation of stevioside: a 
nutraceutical or OTC aid for the diabetic patients. Inventi Nutraceut 2017;2:1-9.

10. Sonkusre N, Dhabarde DM, Mahapatra DK. Formulation and development of mirtazapine self-emulsifying drug delivery system (SEDDS) for enhancement of dissolution profile. Inventi NDDS 2016;3:1-9.

11. Arumugarajan AK, Geetha G, Nayak BS. Preparation and in vitro evaluation of etodolac extended-release tablets prepared by wet granulation method employing Kollidon® SR. Indo Am J Pharm Sci 2015;2:1133-40.
12. Sandhya P, Habeeb S, Sunitha M, Patnaik KSKR, Subrahmanyam CVS. A novel approach in modified release dosage forms formulation and evaluation of oral controlled release matrix tablets of etodolac. Asian J Pharm Res 2013;3:60-5.

13. Panchal KK, Chotai NP. Formulation development and in vitro evaluation of controlled release matrix tablet of etodolac Indian J Pharm Edu Res 2013;47:39-48.

14. Shetty P, Kumar R, Yamunappa, Suvarna P, Narayana SVB. Design and evaluation of sustained release matrix tablets of etodolac. Asian J Pharm Tech 2016;6:1-14. 